Research Article

\title{
Concrete Creep Analysis Method Based on a Long-Term Test of Prestressed Concrete Beam
}

\author{
Mingfang Yang $\mathbb{D},{ }^{1,2}$ Song Jin, ${ }^{1,2}$ and Jinxin Gong $\mathbb{D}^{1,2}$ \\ ${ }^{1}$ Institute of Structural Engineering, Dalian University of Technology, Dalian 116024, China \\ ${ }^{2}$ State Key Laboratory of Coastal and Offshore Engineering, Dalian University of Technology, Dalian 116024, China \\ Correspondence should be addressed to Jinxin Gong; jinxingong2012@gmail.com
}

Received 19 September 2019; Revised 29 December 2019; Accepted 4 January 2020; Published 24 February 2020

Academic Editor: Chiara Bedon

Copyright (C) 2020 Mingfang Yang et al. This is an open access article distributed under the Creative Commons Attribution License, which permits unrestricted use, distribution, and reproduction in any medium, provided the original work is properly cited.

\begin{abstract}
Concrete creep plays a significant role in the long-term performance of the prestressed concrete structure. However, most of the existing prediction models cannot accurately reflect the in-site concrete creep in a bridge construction environment. To improve the prediction accuracy of creep effects in concrete structures, an innovative creep analysis method is developed in this study. Parameters in the creep model in fib MC 2010 have been calibrated with respect to the long-term loading test results of the prestressed concrete beam. The measured strains of concrete and the midspan deflections of the test beam are compared with the predicted results using the creep model in fib MC 2010. It indicates that the results predicted by the calibrated creep model are in good agreement with the test results. However, the results predicted by the creep model in fib MC 2010 significantly deviate from the test results. This proposed creep analysis method can provide a new thought to improve the predicted effect of the creep effects on creep-sensitive structures.
\end{abstract}

\section{Introduction}

Concrete creep plays a significant role in the long-term performance of concrete structures [1-5]. Since the discovery of concrete creep in the early 20th century, relevant scholars have studied it for more than a hundred years. Yet, despite the long history of research, the understanding of concrete creep phenomenon is still far less than complete [6-9]. Except for B3 and B4 creep models developed by Bažant based on microprestress-solidification theory $[10,11]$, creep models developed by other scholars and design codes are empirical models based on laboratory tests [12-18]. Creep in concrete is a highly complex phenomenon, which depends on a wide range of factors. The long-term deflections predicted by the creep models in different design codes have a great difference [19-21]. Bažant et al. [22] analyzed the long-term deflection of Koror-Babeldaob (KB) Bridge in Palau, which collapsed in 1996, using ACI 209, CEB MC 1990, JSCE, GL2000, and B3 creep models. Granata et al. [23] investigated the effects of time-dependent phenomena on prestressed concrete girder bridges and made a compared analysis on the creep behaviors for actual cases of bridges by using the creep prediction models in Eurocode 2, ACI 209, B3, GL2000, and AASHTO 2007. Pan et al. [24] studied the creep strain of the high-strength concrete used in the continuous rigid frame of Sutong Bridge and compared it with the strains estimated by ACI 209, JTG D62-2004, B3, and GL2000 models. Vandewalle [25] investigated the effects of environmental conditions on creep compliance function experimentally and predicted the strain by the models in Eurocode 2 and B3. Yang et al. [26] carried out the experimental analysis of $32 \mathrm{~m}$ precast $\mathrm{PC}$ box girder and compared it with the theoretical results calculated by JTG 2004, fib MC 2010, and GL2000. These comparisons show the significant differences between the predictions supplied by these models especially for delayed deflections at very long times.

So far, many large-span bridges suffer from excessive long-term deflection [22, 27, 28], and the causes of this phenomenon are complicated, among which concrete creep 
is one of the main factors [29]. Accurate prediction of the long-term behavior of the long-span prestressed concrete bridges, reasonable creep, and shrinkage model is indispensable [30]. Due to the complexity of the actual environment condition, it is difficult to simulate accurately. For large and creep-sensitive structures, like long-span bridges, in-site creep test is an alternative way to predict creep in concrete for actual structures accurately. Furthermore, relevant design codes $[17,31]$ recommend this method to determine creep deformation for the actual structures. However, most concrete creep tests are carried out at the standard environmental condition, which is significantly different from the actual environment. The most tough thing is that the concrete creep model based on laboratory test is not reliable in practical engineering. Therefore, it is urgent to establish a creep analysis method suitable for the structures in site conditions.

In this study, long-term creep tests of six T-section beams with different prestressing levels under nonstandard environmental condition are carried out to simulate the insite concrete creep in the bridge construction environment. Based on the test results, an innovative creep analysis method is developed and the parameters in the creep model in fib MC 2010 are calibrated by the least-squares optimization program. The measured strains of concrete and the midspan deflections of the test beams are compared with the predicted results using the creep model in fib MC 2010 and the calibrated creep model proposed in this paper. The objective of this study is to determine the parameters of the creep model with respect to the concrete creep test for a specific engineering project and propose the concrete creep model that meets the actual in-site environmental conditions. It should be noted that the creep model provided here can only be used to calculate the creep of concrete structures under the conditions in this study. The proposed creep analysis method can provide experience for the analysis of structural creep effect.

\section{Experimental Program}

2.1. Details of Specimens. Grade R52.5 Portland cement, gravel with continuous grading size of $5-10 \mathrm{~mm}$ and river sand, is used in this test, and $12 \%$ fly ash and $4 \%$ slag powder are added to the concrete mixture. Table 1 shows the concrete mixture proportions. When casting test beams, twelve $150 \mathrm{~mm} \times 150 \mathrm{~mm} \times 150 \mathrm{~mm}$ cube specimens and six $150 \mathrm{~mm} \times 150 \mathrm{~mm} \times 300 \mathrm{~mm}$ prism specimens were also cast, which were used to test the compressive strength and elastic modulus of concrete, respectively. Among them, six cube specimens and three prismatic specimens cured in the same conditions as the T-section beam.

Six post-tensioned prestressed concrete $\mathrm{T}$-section beams identified as PC1 PC6 with a length of $4 \mathrm{~m}$ were produced. The details of the test prestressed concrete beam are shown in Figure 1(a). The prestressing tendon is made of a single strand, with Young's modulus of $1.95 \times 10^{5} \mathrm{MPa}$, crosssectional area of $139 \mathrm{~mm}^{2}$, and ultimate tensile stress of $1860 \mathrm{MPa}$. To prevent the local crushing failure of concrete, steel anchorage plate and reinforced net are provided. Details of anchorage are shown in Figure 1(b).
TABle 1: Concrete mixtures (unit: $\mathrm{kg} / \mathrm{m}^{3}$ ).

\begin{tabular}{lcccccc}
\hline Cement & Water & Sand & Aggregate & Fly ash & Slag & Admixture \\
\hline 420 & 175 & 692 & 1030 & 60 & 20 & 14.8 \\
\hline
\end{tabular}

Prestressed concrete T-section beams are divided into two groups according to the concrete age at tensioning. Table 2 lists details of stress in prestressing tendons of each test beam, in which $f_{\mathrm{pt}}$ is the ultimate tensile stress of prestressing tendons. The embedded plastic bellow is grouted immediately after tensioning. The grouting material is cement mortar with a water-cement ratio of 0.4 and an expansive agent ratio of $10 \%$.

2.2. Creep Test. A four-point bending strategy is adopted in this experiment. Figure 2(a) shows the prestressed concrete T-section beam in the test. Figure 2(b) shows the arrangement of measuring points (MA and $\mathrm{MB}$ ). The embedded vibrating wire strain gauges (VWSG) are used to measure the strain at each measuring point and the dial indicators are used to measure the deformation development at midspan of the beam. Figures 3(a) to 3(f) illustrate the loading histories of the six beams. It should be noted that loads of PC1, PC2, and PC3 exhibited large fluctuations due to the use of the self-locking hydraulic jacks at the initial stage. Therefore, the self-locking hydraulic jacks were replaced by the mechanical jacks in the subsequent creep tests.

2.3. Test Results and Discussion. The compressive strength test and modulus of elasticity test of concrete were carried out at the age of 28 days. The cubic compressive strength of standard curing specimen is $46.86 \mathrm{MPa}$ and the elastic modulus of prism specimens is $33.62 \times 10^{4} \mathrm{MPa}$. The compressive strength of specimens in the same curing environment as the T-section beam is $42.5 \mathrm{MPa}$ and the elastic modulus is $32.47 \times 10^{4} \mathrm{MPa}$. It can be seen that the difference of the curing environment will affect the compressive strength and modulus of elasticity of concrete.

Figures 4(a) and 4(b) demonstrate the variation of the average daily temperature and the average surrounding relative humidity of the measurement points during the test. It can be seen from Figure 4 that there are two types of fluctuation for temperature and relative humidity; i.e., the small local fluctuation reflects the difference between the daily average temperature and relative humidity, and the large range represents the seasonal variation.

Based on the stress and strain in concrete, the test can be divided into three stages, as shown in Figure 5. From casting concrete to tensioning (Stage I), the strains in this stage are mainly shrinkage strain of concrete. Considering the restraining effect of non-prestressed steel on concrete shrinkage, it will produce tension stress in concrete and compressive stress in non-prestressed steel. From tensioning to apply the external loads (Stage II), the stress in concrete and non-prestressed steel is mainly caused by the prestress force. Due to the time-dependent strain of concrete, the stress and strain in concrete, non-prestressed steel and 


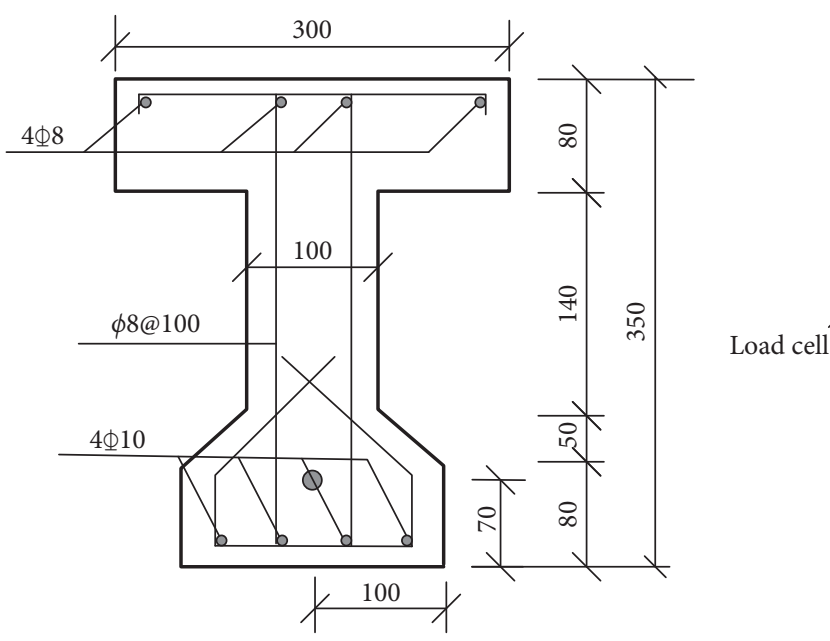

(a)

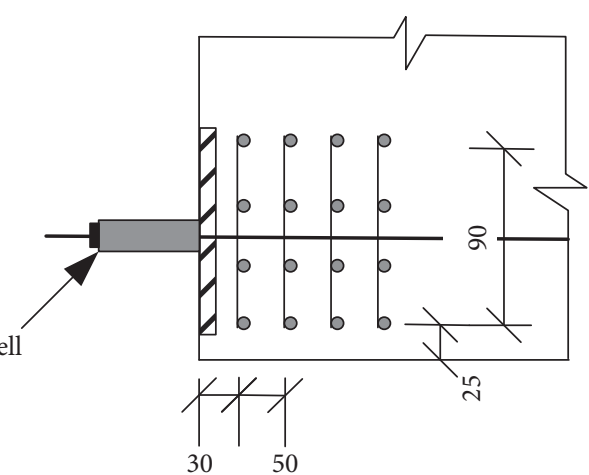

(b)

Figure 1: Configurations of the cross-section and the anchor end (unit: mm): (a) cross-section; (b) anchorage details.

TABLE 2: Concrete age at tensioning and stress in prestressing tendons.

\begin{tabular}{lccc}
\hline Beam number & Age of concrete at tensioning (days) & Jacking force & Prestress after instantaneous losses $(\mathrm{MPa})$ \\
\hline PC1 & 23 & $0.65 f_{\mathrm{pt}}$ & 1014.4 \\
PC2 & 23 & $0.60 f_{\mathrm{pt}}$ & 971.2 \\
PC3 & 23 & $0.65 f_{\mathrm{pt}}$ & 1057.5 \\
PC4 & 45 & $0.70 f_{\mathrm{pt}}$ & 1100.7 \\
PC5 & 45 & $0.75 f_{\mathrm{pt}}$ & 1259.0 \\
PC6 & 45 & $0.73 f_{\mathrm{pt}}$ & 1187.1 \\
\hline
\end{tabular}

prestressing tendons also change with time. With the increase of shrinkage and creep strain of concrete, the stress in prestressing tendons and concrete decreases, and the creep rate of concrete shows a decreasing trend. From the application of the external load to the observation time (Stage III), there is a sudden change of concrete strain due to the external load, which becomes the dominant factor of the concrete stress in this stage. The strain and stress in non-prestressed steel and prestressing tendons still change with the strain of concrete. Table 3 lists the details of the strain at the measuring point for PC1 to PC6. Here, $t_{0}$ and $t_{F}$ are the time of prestressing and applying the external load, respectively. $\varepsilon_{m c, A}\left(t_{0}\right)$ and $\varepsilon_{m c, B}\left(t_{0}\right)$ denote the strains of Points MA and MB at the time of $t_{0}$ under the prestress, respectively. $\varepsilon_{m c, A}\left(t_{0 F}\right)$ and $\varepsilon_{m c, B}\left(t_{0 F}\right)$ denote the strains of Points MA and MB at the time of $t_{F}$ under the prestress, respectively. $\varepsilon_{m c, A}\left(t_{F}\right)$ and $\varepsilon_{m c, B}\left(t_{F}\right)$ represent the strains of Points $\mathrm{MA}$ and $\mathrm{MB}$ at the time of $t_{F}$ under the prestress and external load, respectively.

Figure 6 presents the curves of the total strain of concrete (temperature strain, shrinkage strain, and creep strain) versus time measured at MA and $\mathrm{MB}$ points at the midspan of the specimens PC1-PC6. From Figure 6, it can be seen that the total strain of concrete measured at $\mathrm{MA}$ and $\mathrm{MB}$ is closely related to the temperature variation trend, as indicated in Figure 4(a). During the 200-300d, 500-680d, 850-1050 d, and 1250-1350 d, the temperature tends to rise, and the total strain of concrete tends to increase rapidly.

\section{Creep Analysis Method}

3.1. Calculation of the Strain. After anchorage, the internal forces of concrete, non-prestressed steel, and prestressing tendons are under equilibrium condition (static equilibrium); that is,

$$
N_{c}(t)+N_{s}(t)+N_{p}(t)=N_{c}(t)+\sigma_{s}\left(t, t_{0}\right) A_{s}+\sigma_{p}\left(t, t_{0}\right) A_{p}=0
$$

where $t_{0}$ is the concrete age in days at tensioning; $t$ is the concrete age in days at the moment considered; $N_{c}(t) \in$ is the tensile force in concrete at time $t ; N_{s}(t)$ and $\sigma_{s}\left(t, t_{0}\right)$ are the tensile force and the stress in non-prestressed steel, respectively; $N_{p}(t)$ and $\sigma_{p}\left(t, t_{0}\right)$ are the tensile force and the stress in prestressing tendons, respectively; and $A_{p}$ and $A_{s}$ are the cross-sectional area of prestressing tendons and nonprestressed steel, respectively.

Assuming that concrete is perfectly bonded with nonprestressed steel and prestressing tendons (deformation compatibility condition), then

$$
\begin{gathered}
\varepsilon_{s}\left(t, t_{0}\right)=\Delta \varepsilon_{s c}\left(t, t_{0}\right), \\
\varepsilon_{p}\left(t, t_{0}\right)=\Delta \varepsilon_{p c}\left(t, t_{0}\right),
\end{gathered}
$$

where $\Delta \varepsilon_{s c}\left(t, t_{0}\right)$ and $\Delta \varepsilon_{p c}\left(t, t_{0}\right)$ are the change in strain of concrete at the centroid of non-prestressed steel and prestressing tendons, respectively. 


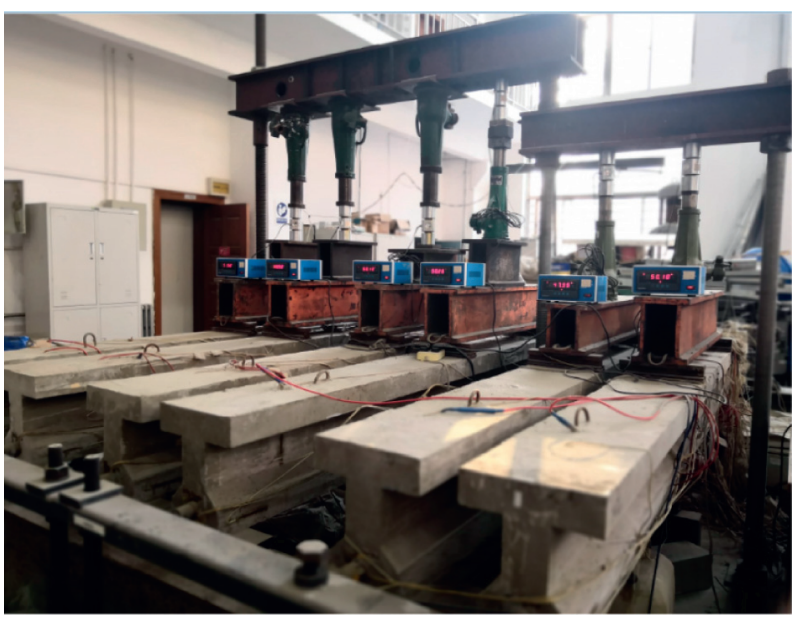

(a)

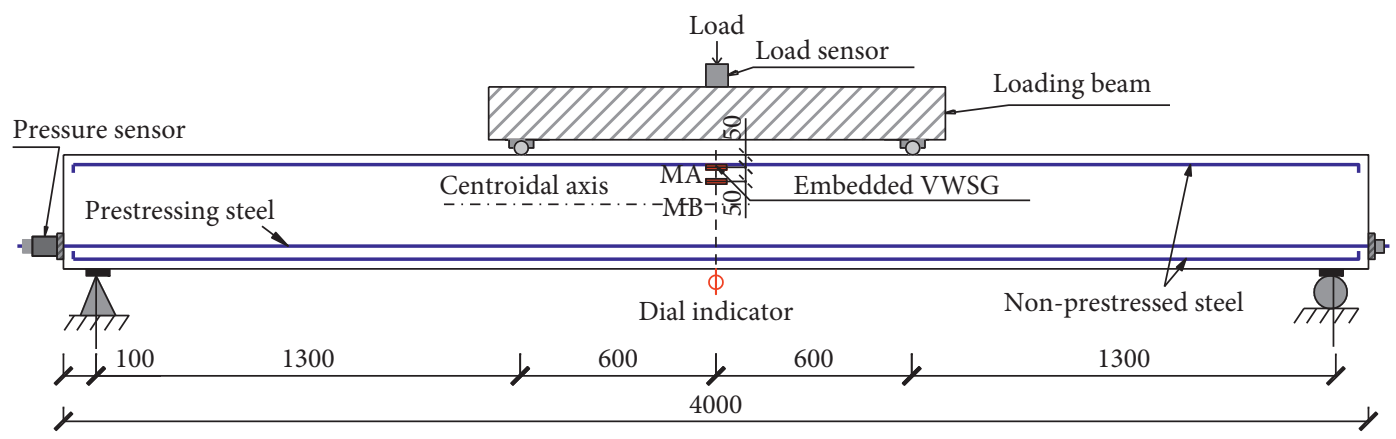

(b)

Figure 2: Creep test of the prestressed concrete beam: (a) photograph of creep specimens and experimental apparatus; (b) structural dimensions and sensor layout of beams.

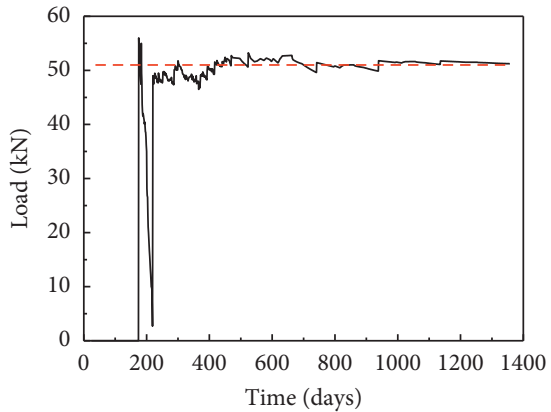

(a)

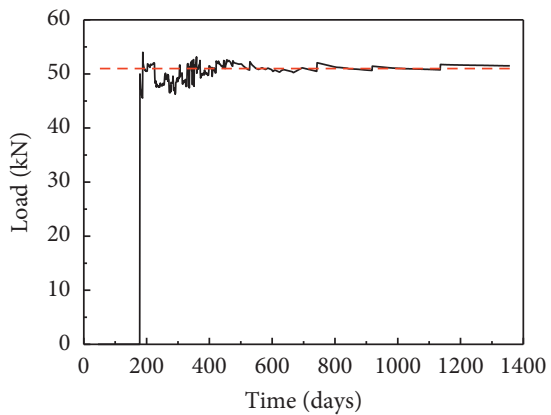

(d)

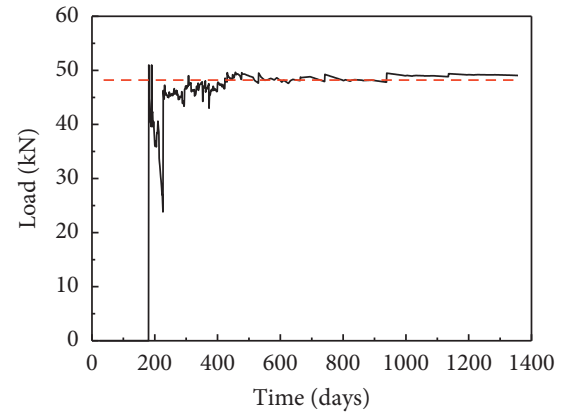

(b)

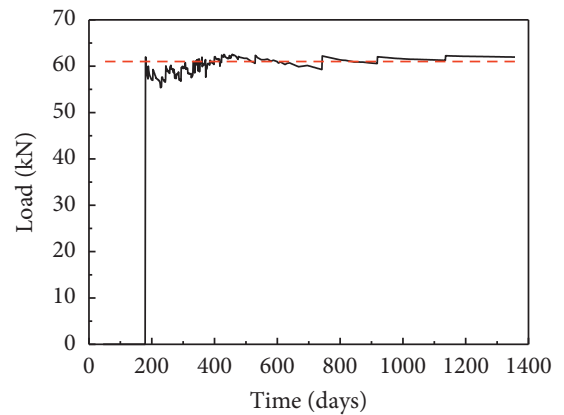

(e)

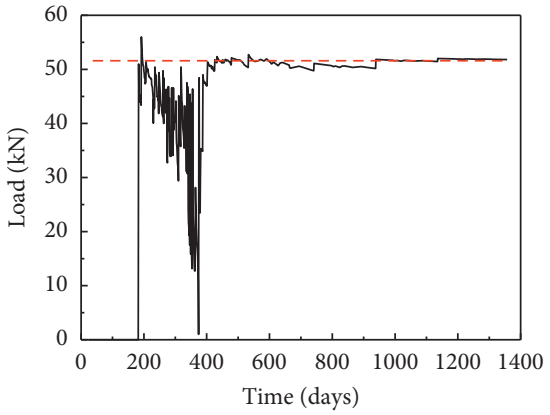

(c)

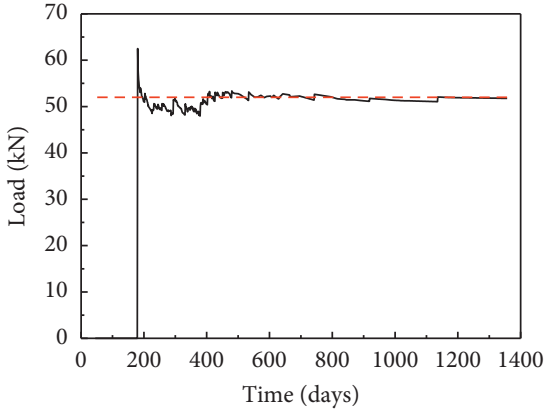

(f)

FIgUre 3: Loading histories of the test beams: (a) PC1; (b) PC2; (c) PC3; (d) PC4; (e) PC5; (f) PC6. 


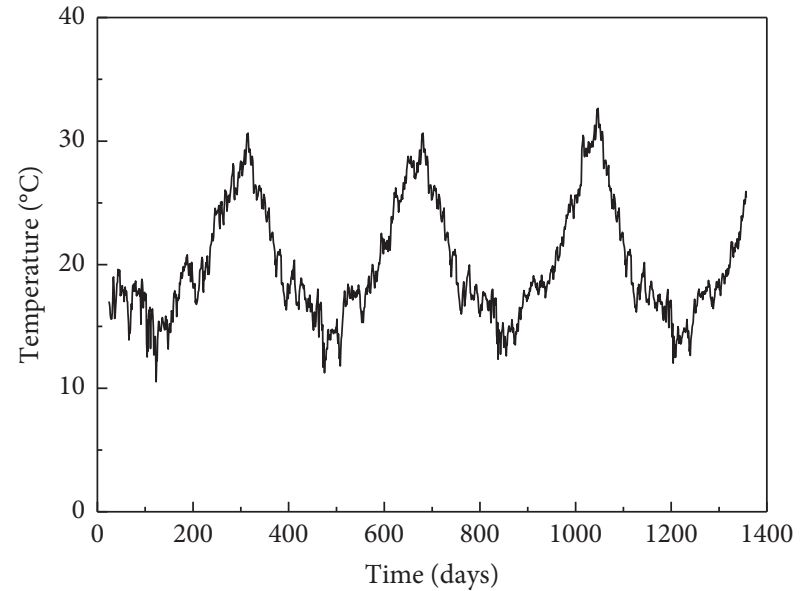

(a)

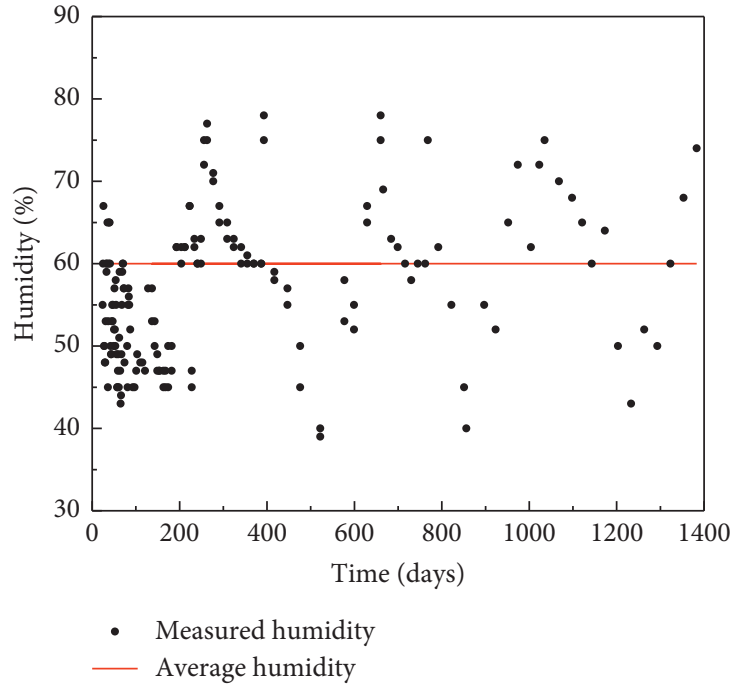

(b)

FIgURe 4: Ambient temperature and relative humidity during the monitoring period: (a) temperature; (b) relative humidity.

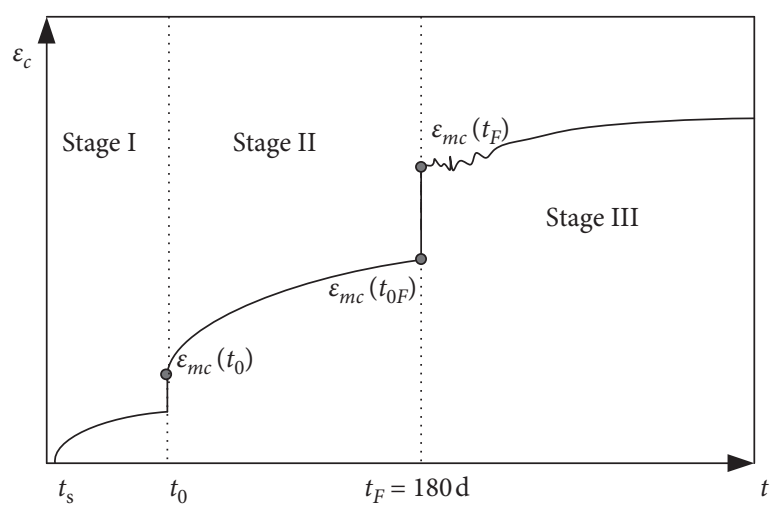

FIGURE 5: Strain variations of the measuring point in the creep tests.

TABLE 3: Values of $\varepsilon_{m c, A}$ and $\varepsilon_{m c, B}$ for each specimen (unit: $\mu \varepsilon$ ).

\begin{tabular}{lcccccc}
\hline \multirow{2}{*}{ Beam number } & \multicolumn{3}{c}{$\varepsilon_{m c, A}$} & \multicolumn{3}{c}{$\varepsilon_{m c, B}$} \\
& $t_{0}$ & $t_{0 F}$ & $t_{\mathrm{F}}$ & $t_{0}$ & $t_{0 F}$ & $t_{F}$ \\
\hline PC1 & 209.26 & 633.79 & 805.57 & 249.58 & 681.57 & 760.15 \\
PC2 & 198.22 & 673.72 & 839.44 & 227.97 & 704.69 & 791.02 \\
PC3 & 220.36 & 707.37 & 845.73 & 249.99 & 741.01 & 816.52 \\
PC4 & 258.47 & 664.45 & 810.17 & 290.18 & 699.87 & 781.90 \\
PC5 & 247.62 & 626.18 & 864.98 & 296.28 & 676.72 & 787.52 \\
PC6 & 256.11 & 629.47 & 812.53 & 302.23 & 679.08 & 783.62 \\
\hline
\end{tabular}

The concrete stress is not constant due to the interaction of the concrete creep and the prestressing loss. On the one hand, the concrete creep results in the prestressing loss. On the other hand, the prestressing loss reduces the concrete stress, which in turn affects the development of concrete creep. For variable stresses condition, the principle of superposition is assumed to be valid. Therefore, the constitutive equation for concrete can be expressed as [12]

$$
\begin{aligned}
\Delta \varepsilon_{c}\left(t, t_{0}\right)= & \Delta \varepsilon_{c r}\left(t, t_{0}\right)+\Delta \varepsilon_{s h}\left(t, t_{0}\right)+\Delta \varepsilon_{T}\left(t, t_{0}\right) \\
= & \sigma_{c}\left(t_{0}\right) J\left(t, t_{0}\right)+\int_{t_{0}}^{t} J(t, \tau) d \sigma_{c}(\tau)+\Delta \varepsilon_{s h}\left(t, t_{0}\right) \\
& +\alpha_{T} \Delta T\left(t, t_{0}\right),
\end{aligned}
$$

where $\Delta \varepsilon_{c r}\left(t, t_{0}\right)$ is the creep strain of concrete from time $t_{0}$ to time $t ; \Delta \varepsilon_{s h}\left(t, t_{0}\right)$ and $\Delta \varepsilon_{T}\left(t, t_{0}\right)$ are the change in shrinkage strain and thermal strain of concrete, respectively; $\sigma_{c}\left(t_{0}\right)$ is the initial stress of concrete at time $t_{0} ; \Delta T\left(t, t_{0}\right)=$ $T(t)-T\left(t_{0}\right)$ is the change in temperature; $T(t)$ and $T\left(t_{0}\right)$ are the temperature of concrete based on the test data at time $t$ and $t_{0}$, respectively; and $\alpha_{T}$ is the thermal expansion coefficient of concrete. $\alpha_{T}=10 \cdot 10^{-6} \mathrm{~K}^{-1}$ for normal weight concrete suggested by fib MC 2010 is used in this study. $J\left(t, t_{0}\right)$ is the creep compliance, which can be expressed as follows according to fib MC 2010 [12].

$$
J\left(t, t_{0}\right)=\frac{1}{E_{\mathrm{c}}\left(t_{0}\right)}+\frac{\varphi\left(t, t_{0}\right)}{E_{\mathrm{c}}},
$$

where $E_{\mathrm{c}}\left(t_{0}\right)$ and $E_{\mathrm{c}}$ are the elastic modulus of the concrete in $\mathrm{MPa}$ at the age of $t_{0}$ and 28 days, respectively; $\varphi\left(t, t_{0}\right)$ is the creep coefficient of concrete, and $t_{0}$ is the initial loading age of concrete in days. It should be noted that the relative humidity takes $60 \%$ as the annual average ambient relative humidity based on the measured data.

The stress of non-prestressed steel can be expressed as

$$
\sigma_{s}\left(t, t_{0}\right)=\varepsilon_{s}\left(t, t_{0}\right) E_{s}
$$




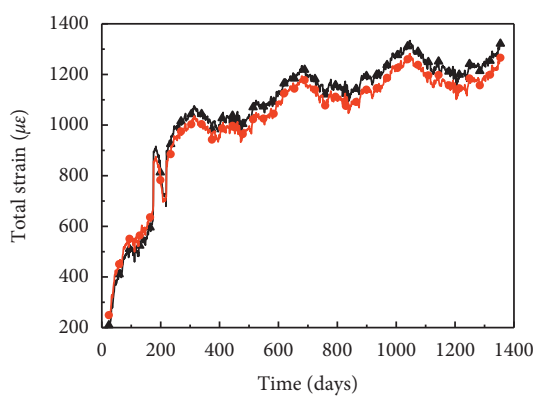

$\rightarrow$ PC1-MA $\because \quad$ PC1-MB

(a)

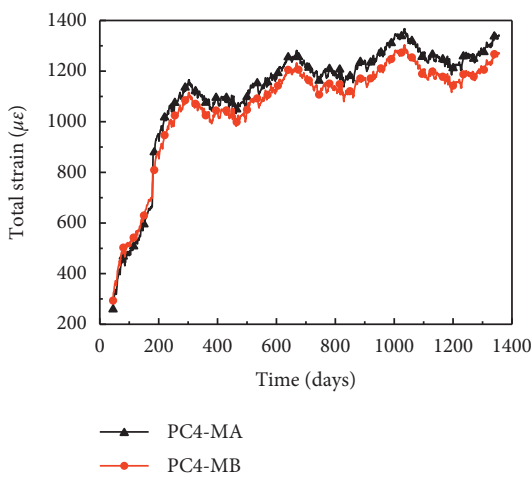

(d)

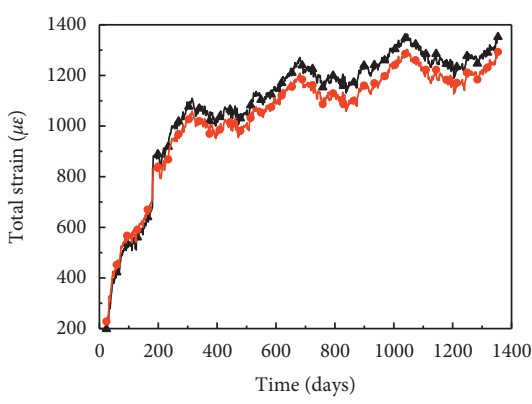

$\multimap \quad \mathrm{PC} 2-\mathrm{MA}$

$\because \quad$ PC2-MB

(b)

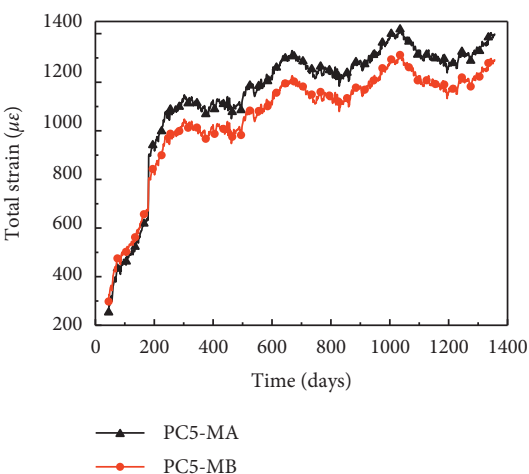

(e)

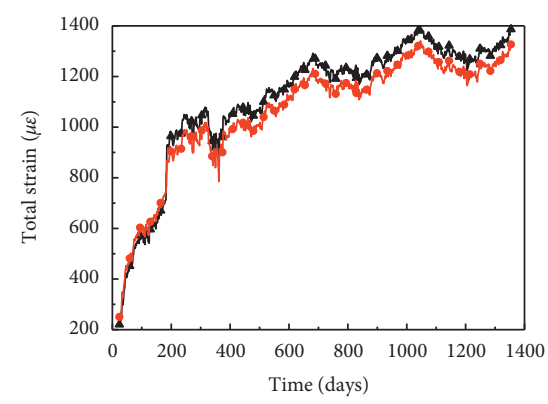

$\multimap$ PC3-MA

$\because$ РС3-МB

(c)

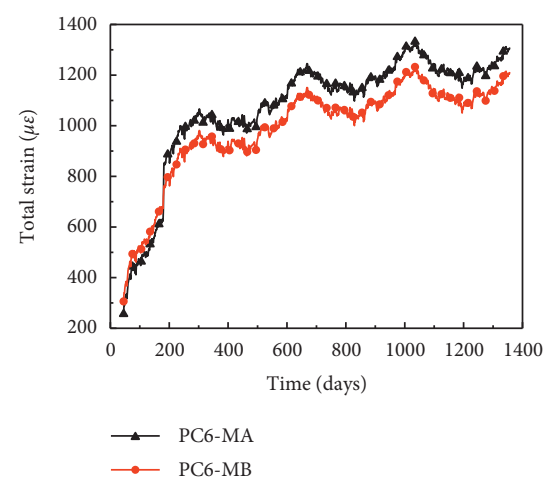

(f)

FIgure 6: The total strain history of test beams: (a) PC1; (b) PC2; (c) PC3; (d) PC4; (e) PC5; (f) PC6.

where $\varepsilon_{s}\left(t, t_{0}\right)$ is the strain in non-prestressed steel from $t_{0}$ to $t ; E_{s}$ is Young's modulus of the non-prestressed steel.

Time-dependent stress of prestressing tendons, which includes stress changes caused by deformation and relaxation of prestressed tendons [31], can be evaluated as

$$
\sigma_{p}\left(t, t_{0}\right)=\varepsilon_{p}\left(t, t_{0}\right) E_{p}+\bar{\sigma}_{p r}\left(t, t_{0}\right)=\varepsilon_{p}\left(t, t_{0}\right) E_{p}+\chi_{r} \sigma_{p r}\left(t, t_{0}\right) \text {, }
$$

where $\varepsilon_{p}\left(t, t_{0}\right)$ is the strain in prestressing tendons from $t_{0}$ to $t ; E_{p}$ is the elastic modulus of the prestressing tendons; $\bar{\sigma}_{p r}\left(t, t_{0}\right)$ is the prestress loss due to relaxation of the prestressed tendons; and $\chi_{r}$ is the relaxation reduction factor. Generally, $\chi_{r}$ is in the range of $0.5 \sim 0.9$ [32-35]. For simplicity, $\chi_{r}=0.8$ is adopted in this study according to the Eurocode [31]. $\sigma_{p r}\left(t, t_{0}\right)$ is the absolute value of stress change in prestressing tendons caused by relaxation and the expression of $\sigma_{p r}\left(t, t_{0}\right)$ can be found in fib MC 2010.

Combined with material mechanics and the plane-section assumption, the stress of concrete at the location interested can be expressed as

$$
\sigma_{c}(t)=\frac{N_{p}(t)}{A_{c}} \pm \frac{N_{p}(t)}{I_{c}} e_{p c} e_{c}+\frac{N_{s}(t)}{A_{c}} \pm \frac{N_{s}(t)}{I_{c}} e_{s c} e_{c} \pm \frac{M_{Q}(t)}{I_{c}} e_{c}
$$

where $A_{c}$ is the cross-sectional area of concrete; $I_{c}$ represents the moment of inertia of cross-section of concrete; $M_{Q}(t)$ is the bending moment caused by the self-weight of the beam and the external load. In stage II, $M_{Q}(t)=M_{g}$, and in stage
III, $M_{Q}(t)=M_{g}+M_{F}(t)$, in which $M_{F}(t)$ is the bending moment induced by the external load. $e_{c}$ denotes the distance from the location interested to the centroid of the concrete section; $e_{s c}$ and $e_{p c}$ are the distance from the centroid of the non-prestressed steel and the prestressing tendons to the centroid of the concrete section, respectively.

According to equation (7), the concrete stress at the centroid of the non-prestressed steel and the prestressing tendons at time $t$ can be expressed as follows:

$$
\begin{gathered}
\sigma_{s c}(t)=\sigma_{p}(t) \rho_{p} \gamma_{p, s}+\sigma_{s}(t) \rho_{s} \gamma_{s, s}-\frac{M_{Q}(t)}{I_{c}} e_{s c}, \\
\sigma_{p c}(t)=\sigma_{p}(t) \rho_{p} \gamma_{p, p}+\sigma_{s}(t) \rho_{s} \gamma_{p, s}-\frac{M_{Q}(t)}{I_{c}} e_{p c}, \\
\sigma_{m c}(t)=\sigma_{p}(t) \rho_{p} \gamma_{p, m}+\sigma_{s}(t) \rho_{s} \gamma_{s, m}+\frac{M_{Q}(t)}{I_{c}} e_{m c},
\end{gathered}
$$

where $e_{m c}$ is the distance from the measuring point to the centroid of the concrete section; $\rho_{s}$ and $\rho_{p}$ are the reinforcement ratio of non-prestressed steel and prestressing tendons, respectively; and $r_{i, j}=\left(1 \pm\left(A_{c} / I_{c}\right) e_{i c} e_{j c}\right)$, in which $i$ and $j$ represent the $p, s$ and $m$, where the subscript $p c, s c$ and $m c$ represent the concrete at the centroid of prestressing tendons, the concrete at the centroid of non-prestressed steel, and the concrete at the measuring points, respectively. If $e_{i c}$ and $e_{j c}$ are on the same side of the centroid of the section, take "+." Otherwise, take “-." 

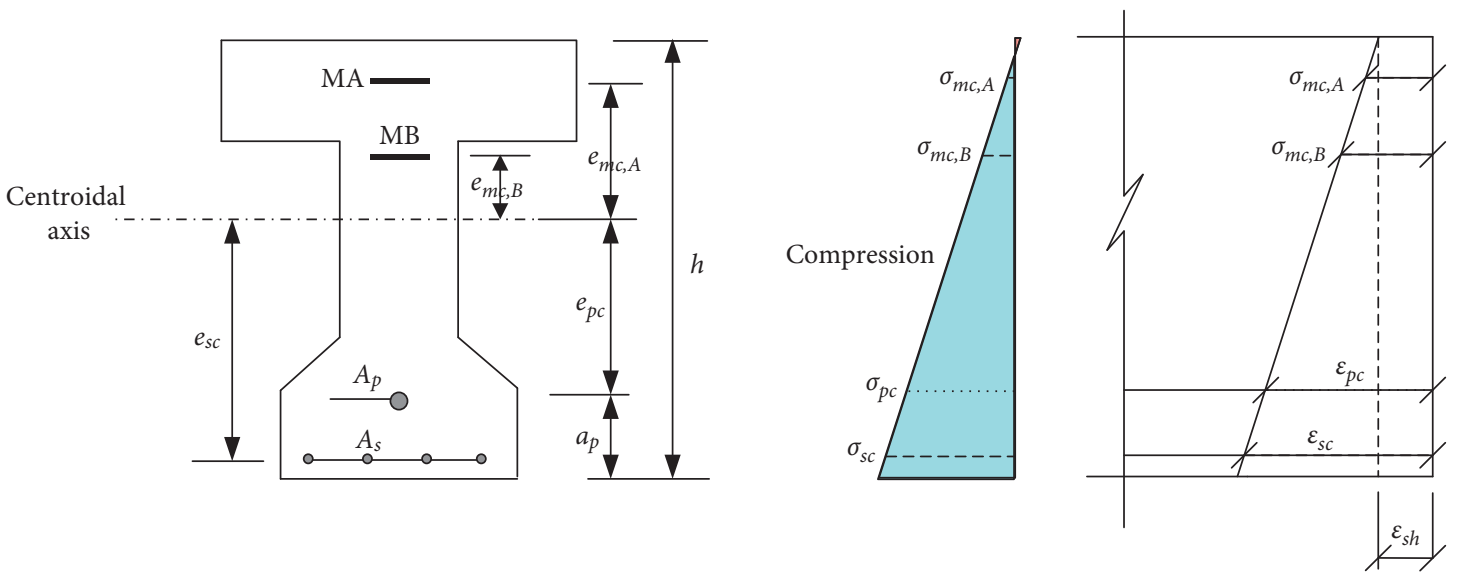

(a)
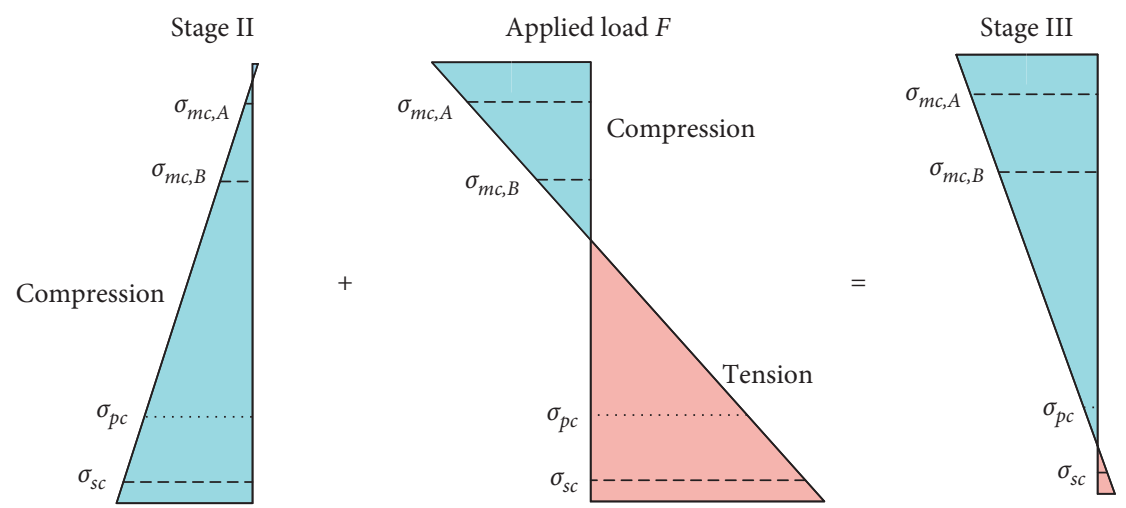

(b)

Figure 7: The stress and strain distributions of cross-section: (a) Stage II; (b) Stage III.

Figures 7 (a) and 7(b) show the stress and strain distributions for the section of the test beam in Stage II $\left(t_{0} \leq t<t_{F}\right)$ and Stage III $\left(t \geq t_{F}\right)$, respectively. In Figure 7 , $e_{m c, A}$ and $e_{m c, B}$ are the distance from the measuring points $\mathrm{MA}$ and $\mathrm{MB}$ to the centroid of the concrete section, respectively. $\sigma_{m c, A}$ and $\sigma_{m c, B}$ are the stress in concrete at the measuring points $\mathrm{MA}$ and $\mathrm{MB}$, respectively.

The instantaneous prestress force measured from the load sensors after anchorage is taken as the initial prestress force. The bending moment at time $t_{0}$ is determined with respect to the self-weight of the concrete. According to the initial conditions, and equations (1)-(3), (5), and (8a), the tensile force in the non-prestressed steel at time $t_{0}$ can be obtained as follows:

$$
N_{s}\left(t_{0}\right)=\frac{\left(N_{p}\left(t_{0}\right) / A_{p}\right) \rho_{p} \gamma_{p, s}-\left(M_{Q}\left(t_{0}\right) / I_{c}\right) e_{s c}}{\left(E_{c}\left(t_{0}\right) / E_{s}\right)-\rho_{s} \gamma_{s, s}} A_{s} .
$$

The step-by-step approach is used in the following analysis. The time interval $\left[t_{0}, t\right]$ is subdivided into a number of subintervals with variant time increment. The time interval $\Delta t_{i}$ increases from 0.01 days to 10 days in this study $\left(\Delta t_{i}=0.01 \mathrm{~d}\right.$ for $t \leq 7 \mathrm{~d} ; \Delta t_{i}=0.5 \mathrm{~d}$ for $7 \mathrm{~d}<t \leq 30 \mathrm{~d} ; \Delta t_{i}=1 \mathrm{~d}$ for $30 \mathrm{~d}<t \leq 365 \mathrm{~d} ; \Delta t_{i}=5 \mathrm{~d}$ for $365 \mathrm{~d}<t \leq 700 \mathrm{~d} ; \Delta t_{i}=10 \mathrm{~d}$ for $t>700 \mathrm{~d})$. The stress increment $\Delta \sigma_{c}\left(t_{i}\right)$ is assumed to be constant in a time interval $\Delta t_{i}$ and applied at the beginning of the ith interval as can be seen in Figure 8. Therefore, equation (3) can be rewritten as [36]

$$
\begin{aligned}
\varepsilon_{c}\left(t, t_{0}\right)= & \sigma_{c}\left(t_{0}\right) J\left(t, t_{0}\right)+\sum_{t_{i}=t_{1}}^{t} \Delta \sigma_{c}\left(t_{i}\right) J\left(t, t_{i}\right)+\varepsilon_{s h}\left(t, t_{0}\right) \\
& +\alpha_{T} \Delta T\left(t, t_{0}\right) .
\end{aligned}
$$

It should be noted that the stress of concrete in Stage I is minimal. Therefore, it is not included in the strain analysis of the test beams.

3.2. Calibration of the Creep Model and Verification. In general, the creep models given in the codes are based on a large number of laboratory tests, which generally reflects the trends of concrete creep. However, there are significant differences between the creep strain calculated by the creep model in the code and the measured strain in actual structures. The main reason is that the environmental conditions on the site are quite different from the environmental conditions in the laboratory. For large-span prestressed concrete bridges, which are sensitive to concrete creep, it is necessary to establish a creep analysis method suitable for site conditions. Therefore, an innovative creep 


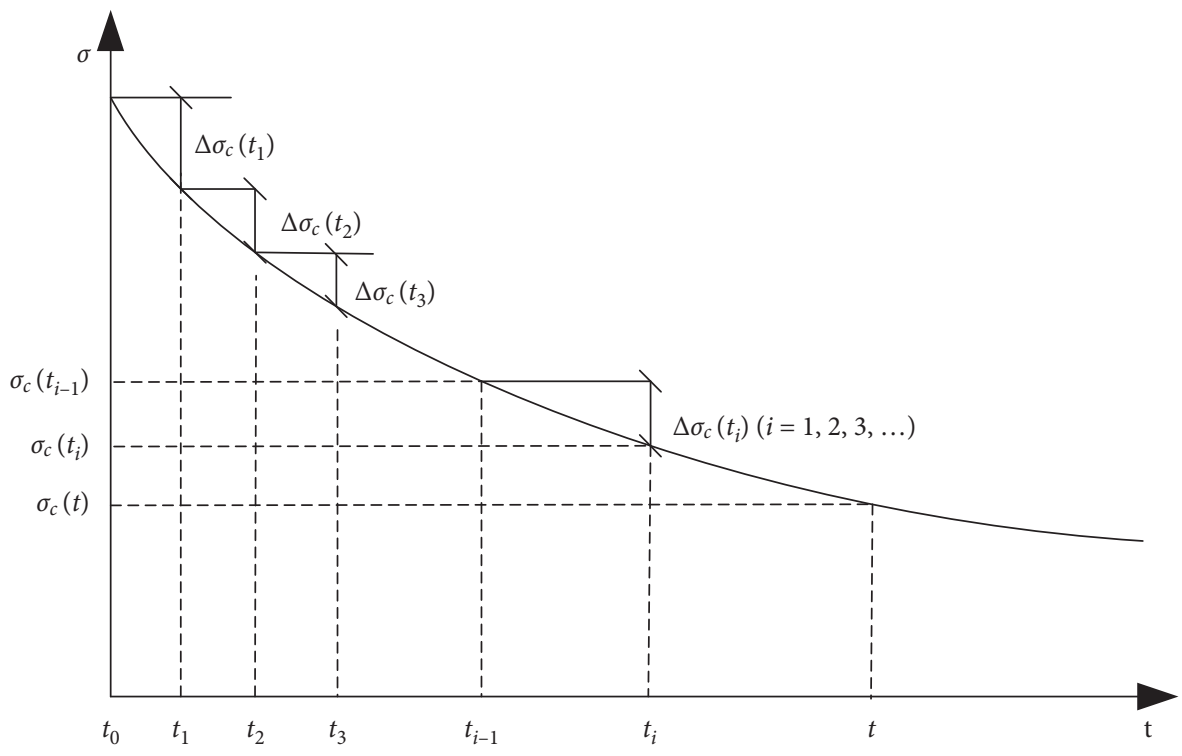

Figure 8: Stress and time intervals for the step-by-step method.

analysis method is proposed in this study based on member tests.

The creep coefficient in the proposed creep analysis methodology can be expressed as

$$
\begin{aligned}
\varphi\left(t, t_{0}\right)= & \varphi_{b c}\left(t, t_{0}\right)+\varphi_{d c}\left(t, t_{0}\right) \\
= & \alpha_{c 1} \ln \left[\left(\frac{30}{t_{0}}+0.035\right)^{\alpha_{c 2}}\left(t, t_{0}\right)^{\alpha_{c 3}}+1\right] \\
& +\alpha_{c 4}\left[\frac{\left(t, t_{0}\right)^{\alpha_{c 5}}}{\beta_{h}+\left(t, t_{0}\right)^{\alpha_{c 5}}}\right]^{\alpha_{c 6}} \frac{1}{0.1+t_{0}^{\alpha_{c 7}}},
\end{aligned}
$$

where $\alpha_{c 1}, \alpha_{c 2}, \alpha_{c 3}, \alpha_{c 4}, \alpha_{c 5}, \alpha_{c 6}$, and $\alpha_{c 7}$ are parameters.

According to the principle of least squares, the estimators of parameters given in equation (11) are the solution of the following optimization problem:

$$
\begin{array}{r}
F=\min \left(\sum_{i=1}^{n}\left(\varepsilon_{m c, i}-\varepsilon_{c a l, i}\right)^{2}\right) \\
\left(\alpha_{c 1}, \ldots, \alpha_{c 7}\right),
\end{array}
$$

where $\varepsilon_{m c, i}$ is the strain of concrete measured from the test at time $t_{i} ; \varepsilon_{c a l, i}$ is the calculated strain of concrete at time $t_{i} ; n$ is the total number of measured values.

To quantify the difference between the calculated and the measured strains more clearly, the errors are normalized and the error coefficient $R(\varepsilon)$ is defined as follows in this paper:

$$
R(\varepsilon)=\frac{1}{\bar{\varepsilon}_{m c}} \sqrt{\frac{1}{n} \sum_{i=1}^{n}\left(\varepsilon_{m c, i}-\varepsilon_{c a l, i}\right)^{2}} \times 100 \%,
$$

where $\bar{\varepsilon}_{m c}$ is the average strain of concrete at all measuring points.

The flow chart for determining parameters of the creep model is shown in Figure 9.
The optimization program is developed according to the flowchart mentioned previously. Table 4 lists the parameters obtained from the optimization program and the corresponding error coefficient. It is generally accepted that the smaller the $R(\varepsilon)$, the smaller the error between the calculated value and the measured value, and vice versa. It can be seen from Table 4 that the creep method presented in this paper can significantly reduce the error coefficient. Figure 10 shows the comparison between the measured concrete strains and the concrete strains predicted by the creep model in fib MC 2010 and the calibrated creep model. It can be seen that the concrete strains predicted by the calibrated creep model are in good agreement with the test strains. However, the concrete strains calculated with respect to the creep models provided in fib MC 2010 are smaller than the measured values. This means that the creep models given by fib MC 2010 do not necessarily accurately predict concrete strain for the specific conditions. It should be noted that the thermal strains of concrete have been subtracted from the total strains to compare clearly. It can be seen from Figure 10 that, after subtracting the thermal strains, the flat branches and ascending branches of concrete strain evolution curves as shown in Figure 6 vanish.

\section{Analysis of the Deflection}

Based on the creep analysis methodology mentioned previously, the deflections of the test beam at the midspan are calculated and compared with the test results below. The relationship between the deflection and curvature can be described as

$$
w^{\prime \prime}(t, x)=\frac{1}{R(t, x)}=\frac{1}{2}\left[\frac{\varepsilon_{p c}\left(t, t_{0}, x\right)}{e_{p c}}+\frac{\varepsilon_{s c}\left(t, t_{0}, x\right)}{e_{s c}}\right],
$$

where $R(t, x)$ is the radius of curvature for the section $x$ at time $t ; x$ is the distance from the section interested to the support; $\varepsilon_{p c}\left(t, t_{0}, x\right)$ and $\varepsilon_{s c}\left(t, t_{0}, x\right)$ are the concrete strain 


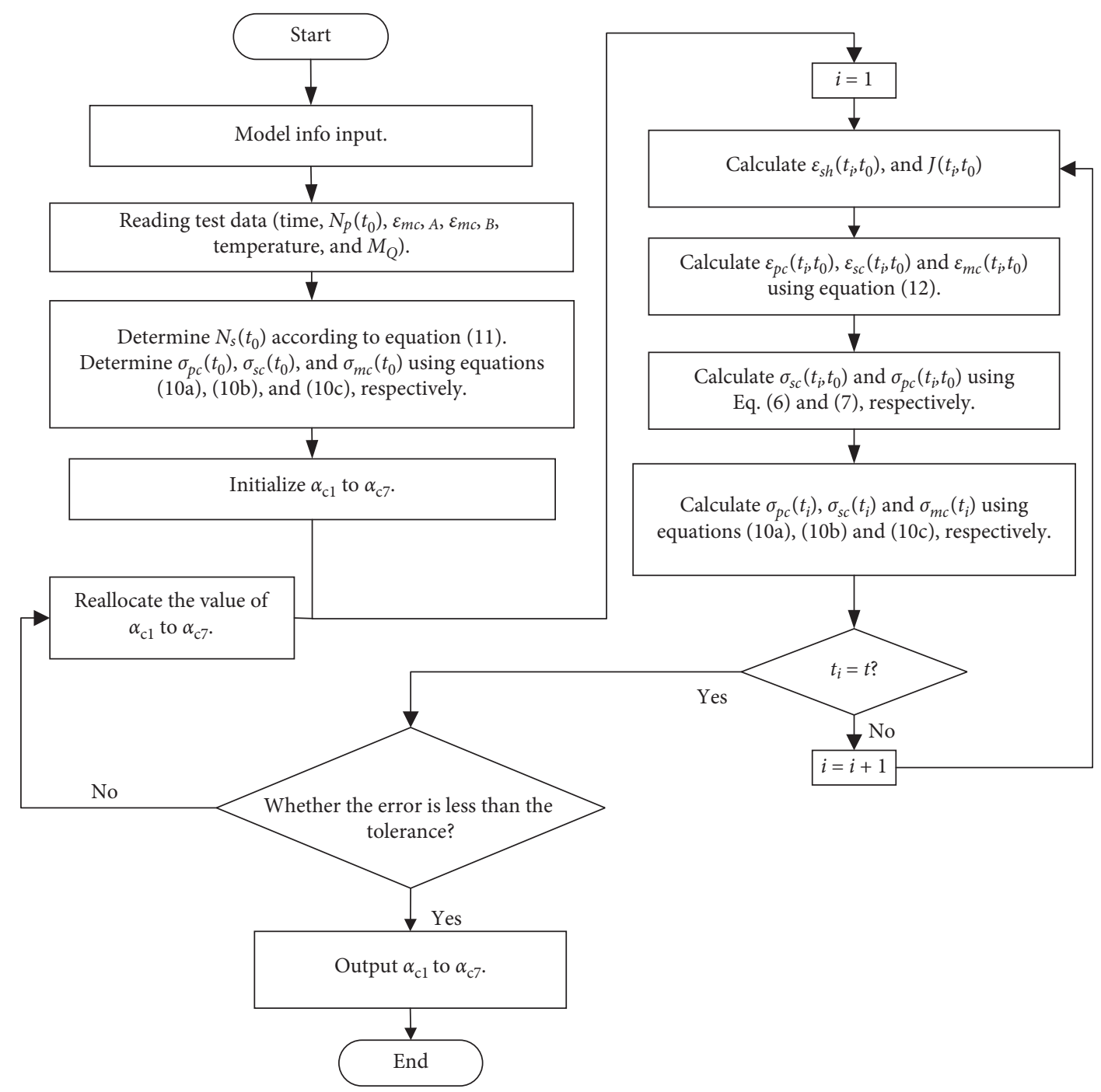

FIgURE 9: Flow chart for determining the parameters.

TABLE 4: The original value and adjusted value of the parameters.

\begin{tabular}{cccccccccc}
\hline \multicolumn{2}{c}{ Parameters } & $\alpha_{c 1}$ & $\alpha_{c 2}$ & $\alpha_{c 3}$ & $\alpha_{c 4}$ & $\alpha_{c 5}$ & $\alpha_{c 6}$ & $\alpha_{c 7}$ & $R(\varepsilon)$ \\
\hline \multirow{2}{*}{ fib MC 2010 } & Original & 0.13 & 2.0 & 1.0 & 1.9 & 1.0 & 0.35 & 0.2 & $21 \%$ \\
& Adjusted & 0.14 & 2.0 & 0.8 & 2.2 & 1.3 & 0.6 & 0.08 & $6 \%$ \\
\hline
\end{tabular}

for the section $x$ at the centroid of the prestress tendons and the non-prestressed steel, respectively.

The beam is divided into $(m-1)$ segments, each with a length of $\Delta x$ along the length direction, as illustrated in Figure 11. The deflection of the $k-1$ th, $k$ th, and $k+1$ th segments at time $t$ is $w_{k-1}(t), w_{k}(t)$ and $w_{k+1}(t)$, respectively. The radius of curvature of the $k$ th segment at time $t$ is $R_{k}(t)$. Figure 12 shows the geometric relationship between deflection and radius of curvature and the deflection angle $\theta(t)$. Considering that the radius of curvature is much larger than $\Delta x$, the relationship between the deflection angle and the deflection and the relationship between the deflection angle and the radius of curvature can be approximately expressed as

$$
\begin{aligned}
\theta(t) & \approx-\frac{w_{k-1}(t)-w_{k}(t)}{\Delta x}, \\
\theta(t) & \approx-\frac{w_{k+1}(t)-w_{k}(t)}{\Delta x}, \\
2 \theta(t) & \approx \frac{\Delta x}{R_{k}(t)} .
\end{aligned}
$$

According to equations (15a)-(15c), the following expression can be obtained:

$$
w_{k-1}(t)-2 w_{k}(t)+w_{k+1}(t)=\frac{-(\Delta x)^{2}}{R_{k}(t)} .
$$



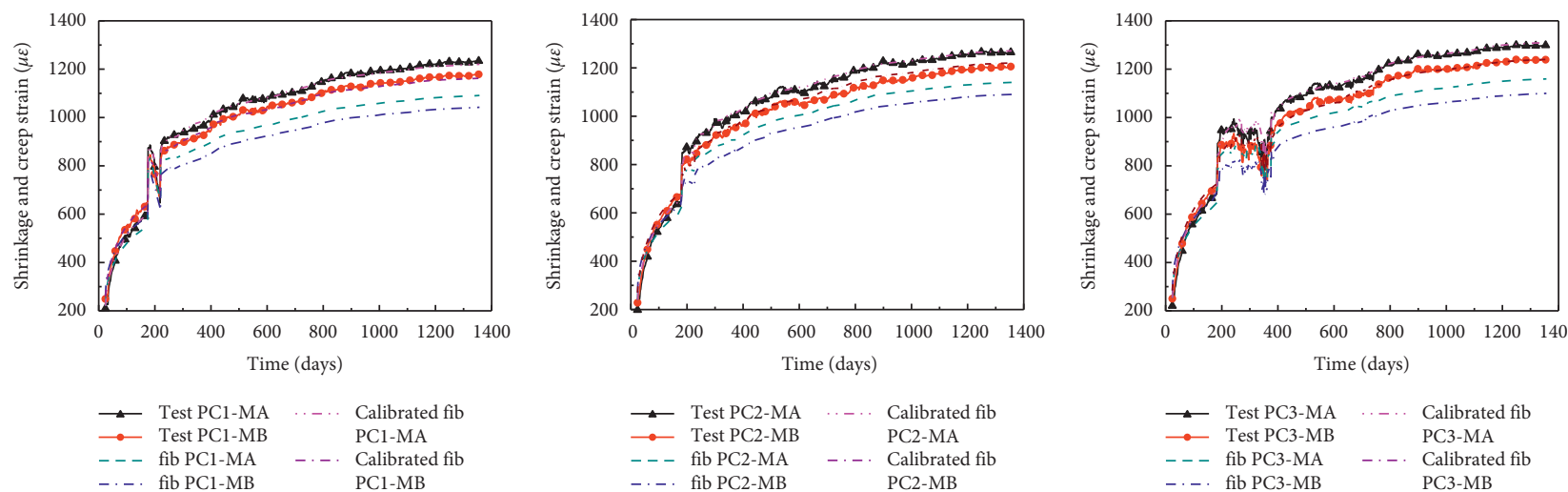

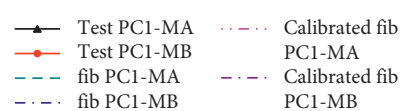

(a)

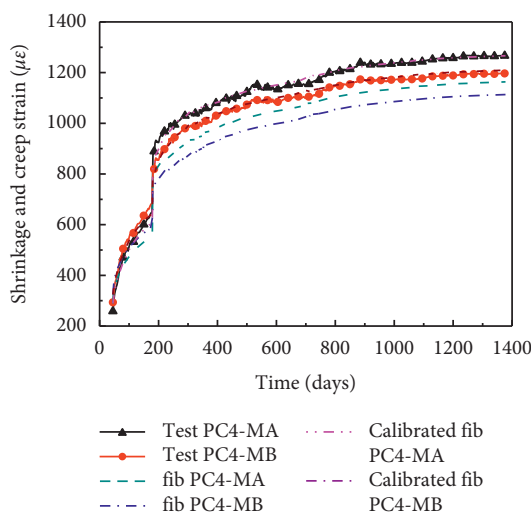

(d)

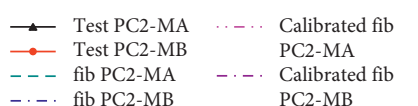

(b)
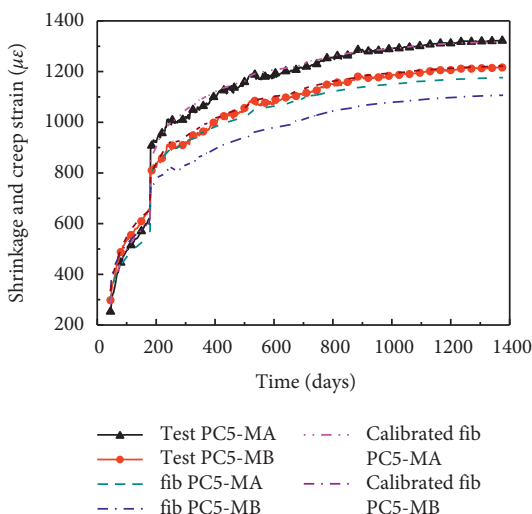

(e) (c)
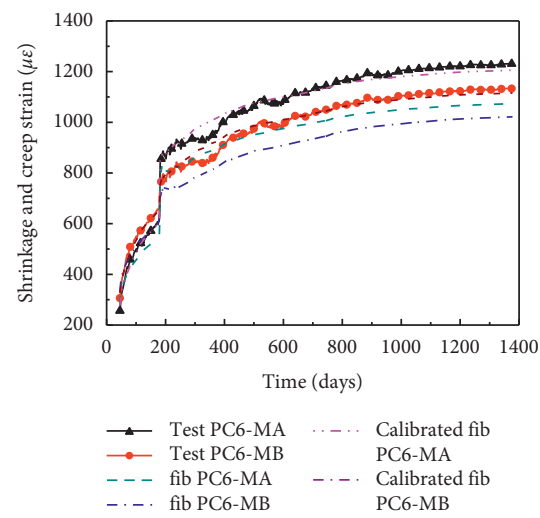

(f)

FIgUre 10: Comparison between the experimental and the predicted strains: (a) PC1; (b) PC2; (c) PC3; (d) PC4; (e) PC5; (f) PC6.

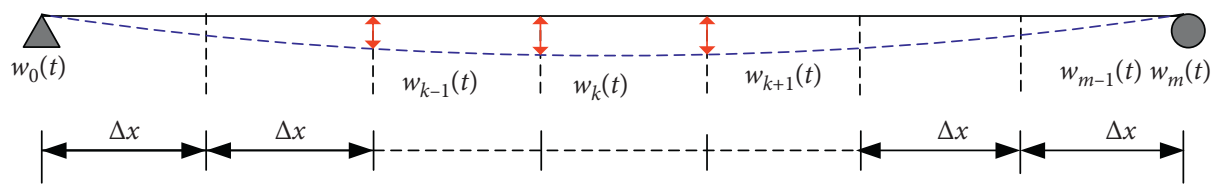

Figure 11: Segment division of the beam.

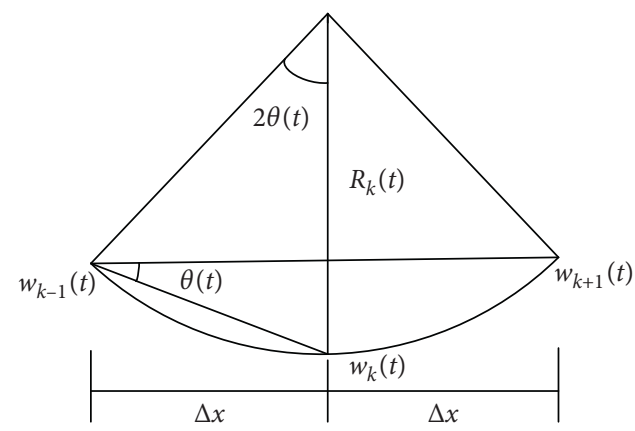

FIgURE 12: Geometric relationship between deflection and radius of curvature. 


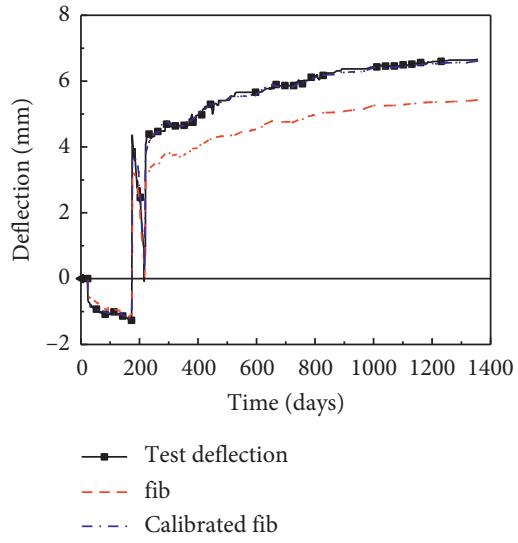

(a)

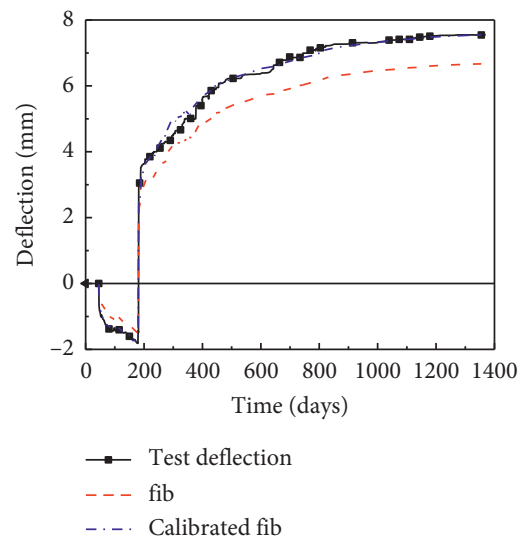

(d)

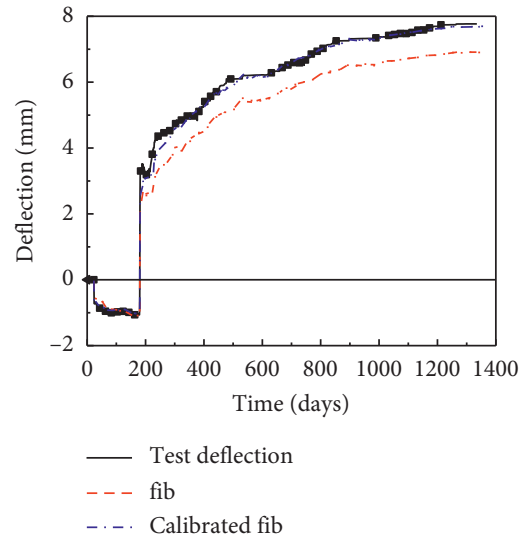

(b)

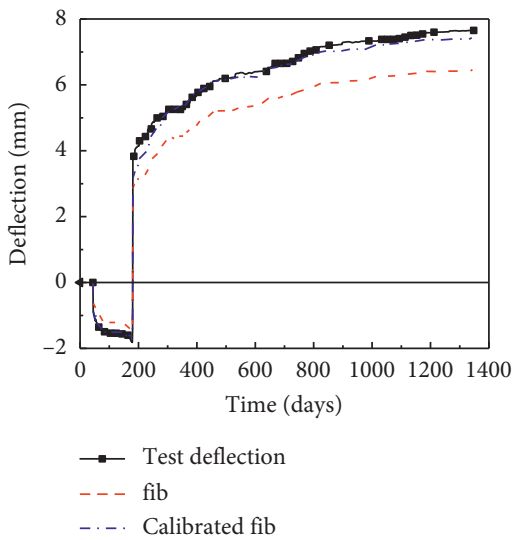

(e)

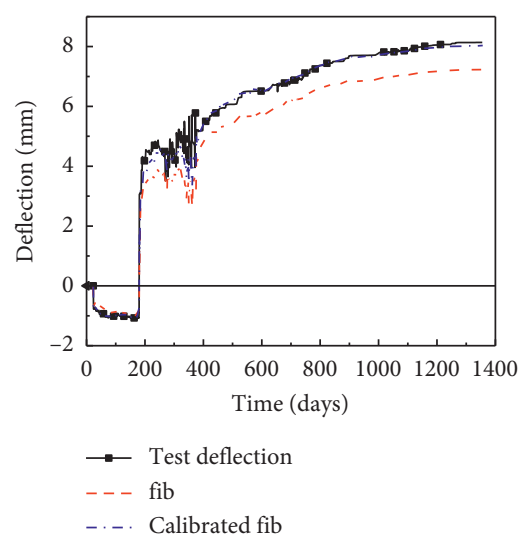

(c)

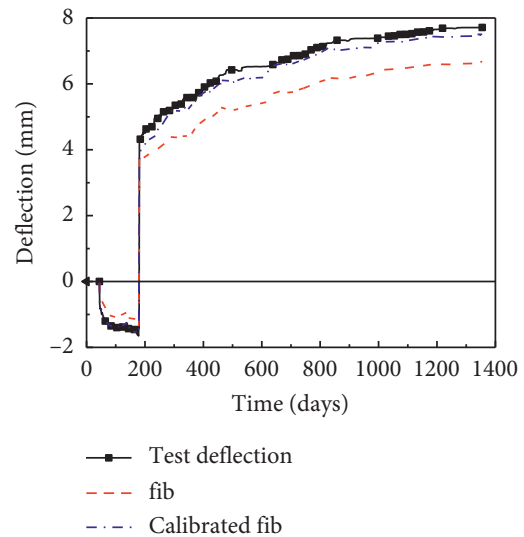

(f)

Figure 13: Comparison between the predicted deflection and the test deflection at the midspan of the test beams: (a) PC1; (b) PC2; (c) PC3; (d) PC4; (e) PC5; (f) PC6.

The linear system of equations can be expressed as

$$
\left\{\begin{array}{l}
w_{0}(t)-2 w_{1}(t)+w_{2}(t)=\frac{-(\Delta x)^{2}}{R_{1}(t)}, \\
w_{1}(t)-2 w_{2}(t)+w_{3}(t)=\frac{-(\Delta x)^{2}}{R_{2}(t)}, \\
\vdots \\
w_{m-2}(t)-2 w_{m-1}(t)+w_{m}(t)=\frac{-(\Delta x)^{2}}{R_{m-1}(t)} .
\end{array}\right.
$$

According to the boundary conditions $\left(w_{0}(t) \equiv 0\right.$, $\left.w_{m}(t) \equiv 0\right)$ and equations (14) and (17), the deflection of the midspan can be obtained.

Figure 13 demonstrates a comparison between the predicted midspan deflections and the measured deflections. From Figure 13, it can be seen that the midspan deflections calculated by the calibrated creep model are in good agreement with the measured deflections; however, the creep model in fib MC 2010 underestimates the midspan deflections, which indicates the superiority of the proposed method.

\section{Conclusions and Remarks}

This paper deals with the realistic creep analysis for practical prestressed concrete structures. Long-term creep tests of six T-section prestressed concrete beams with different prestressing levels are carried out. The strains of concrete and the midspan deflections of the test beam are monitored and analyzed. To improve the prediction accuracy of creep effects in concrete structures, an innovative creep analysis method on the basis of the prestressed concrete test results is proposed. The analysis in this study is based on the creep model recommended in fib MC 2010. This paper can be considered to have successfully achieved the following objectives:

(1) Developed an innovative creep analysis method based on the superposition principle of creep and the creep model in fib MC 2010.

(2) Calibrated the corresponding parameters of the creep model on the basis of the optimization program and the prestressed concrete test results. 
(3) Successfully predicted the actual concrete strain evolution and verified the innovative creep analysis method by the deflection of the midspan of test beams.

The proposed method can provide a reference for creep prediction of prestressed concrete structures, which are sensitive to concrete creep and need a creep model suitable for the structures in site conditions. It must be pointed out that the calibrated creep model can only be used to calculate the creep of a certain concrete under the specific field conditions and cannot be used for other situations. In addition, the concrete shrinkage model used in long-span prestressed concrete structures should also be modified according to the field measured data.

\section{Data Availability}

Some or all data, models, or code generated or used during the study are available from the corresponding author upon request.

\section{Conflicts of Interest}

The authors declare that they have no conflicts of interest.

\section{Acknowledgments}

The authors gratefully acknowledge the financial support from the National Basic Research Program of China (973 Program) under the grant of 2015CB057703.

\section{References}

[1] A. B. Giorla, Implementation of Concrete Creep Model in Grizzly, Oak Ridge National Lab.(ORNL), Oak Ridge, TN, USA, 2017.

[2] G. Di Luzio, R. Felicetti, and L. Cedolin, "Numerical and experimental study of creep and shrinkage in a high-performance concrete," in Proceedings of the CONCREEP 10, pp. 128-137, Vienna, Austria, September 2015.

[3] J.-F. Barthélémy, J.-P. Sellin, and J.-M. Torrenti, “The effects of long-term behavior of both concrete and prestressing tendons on the delayed deflection of a prestressed structure," in Proceedings of the CONCREEP 10, pp. 621-630, Vienna, Austria, September 2015.

[4] Z. P. Bažant and M. Jirásek, "Basic properties of concrete creep, shrinkage, and drying," in Creep and Hygrothermal Effects in Concrete Structures, pp. 29-62, Springer, Berlin, Germany, 2018.

[5] S. Liang and Y. Wei, "Methodology of obtaining intrinsic creep property of concrete by flexural deflection test," Cement and Concrete Composites, vol. 97, pp. 288-299, 2019.

[6] A. R. Marí, J. M. Bairán, and N. Duarte, "Long-term deflections in cracked reinforced concrete flexural members," Engineering Structures, vol. 32, no. 3, pp. 829-842, 2010.

[7] I. H. Yang, "Uncertainty and sensitivity analysis of timedependent effects in concrete structures," Engineering Structures, vol. 29, no. 7, pp. 1366-1374, 2007.

[8] I. H. Yang, "Prediction of time-dependent effects in concrete structures using early measurement data," Engineering Structures, vol. 29, no. 10, pp. 2701-2710, 2007.
[9] Z. Pan and S. Meng, "Three-level experimental approach for creep and shrinkage of high-strength high-performance concrete," Engineering Structures, vol. 120, pp. 23-36, 2016.

[10] Z. P. Bazant and S. Baweja, "Creep and shrinkage prediction model for analysis and design of concrete structures: model B3," ACI Special Publications, vol. 194, pp. 1-84, 2000.

[11] Z. P. Bazant, M. Hubler, and R. Wendner, Model B4 for Creep, Drying Shrinkage and Autogenous Shrinkage of Normal and High-Strength Concretes with Multi-Decade Applicability, RILEM Technical Committee, Paris, France, 2015.

[12] FIB and IFfSC, fib Model Code for Concrete Structures 2010, Ernst \& Sohn, Ulm, Germany, 2013.

[13] ACI 209R-82, Prediction of Creep, Shrinkage, and Temperature Effects in Concrete Structures, American Concrete Institute, Farmington Hills, MI, USA, 1992.

[14] ACI 209.2R-08, Guide for Modeling and Calculating Shrinkage and Creep in Hardened Concrete, American Concrete Institute, Farmington Hills, MI, USA, 2008.

[15] AASHTO, "L. AASHTO LRFD bridge design specifications," in Transportation (Amst), American Association of State Highway and Transportation Officials, Inc., Washington, DC, USA, 2014.

[16] Comite Europeen De Normalisation, Eurocode 2: Design of Concrete Structures. Part 1. General Rules and Rules for Buildings, British Standards Institution, Brussels, Belgium, 2004.

[17] MOT, Specifications for Design of Highway Reinforced Concrete and Prestressed Concrete Bridge and Culverts, China Communications Press, Beijing, China, 2018.

[18] N. Gardner and M. Lockman, "Design provisions for drying shrinkage and creep of normal-strength concrete," ACI Materials Journal, vol. 98, no. 2, pp. 159-167, 2001.

[19] M. S. Saiidi, J. Shields, D. O'Connor, and E. Hutchens, "Variation of prestress force in a prestressed concrete bridge during the first 30 months," PCI Journal, vol. 41, no. 5, pp. 66-72, 1996.

[20] M. Yang and J. Gong, "Survey and investigation of performance of superstructure of long span bridges in China," in Proceedings of International Conference on Performance-based and Life-cycle Structural Engineering, pp. 1210-1219, Brisbane, Australia, December 2015.

[21] W. Xue, T. Liu, and M. Zeng, "Prediction of long-term deflections for high-speed railway prestressed concrete beams," ACI Structural Journal, vol. 113, no. 4, pp. 769-778, 2016.

[22] Z. P. Bažant, Q. Yu, and G.-H. Li, "Excessive long-time deflections of prestressed box girders. I: record-span bridge in Palau and other paradigms," Journal of Structural Engineering, vol. 138, no. 6, pp. 676-686, 2012.

[23] M. F. Granata, P. Margiotta, and M. Arici, "Simplified procedure for evaluating the effects of creep and shrinkage on prestressed concrete girder bridges and the application of European and North American prediction models," Journal of Bridge Engineering, vol. 18, no. 12, pp. 1281-1297, 2013.

[24] Z. Pan, Z. Lü, and C. C. Fu, "Experimental study on creep and shrinkage of high-strength plain concrete and reinforced concrete," Advances in Structural Engineering, vol. 14, no. 2, pp. 235-247, 2011.

[25] L. Vandewalle, "Concrete creep and shrinkage at cyclic ambient conditions," Cement and Concrete Composites, vol. 22, no. 3, pp. 201-208, 2000.

[26] J. X. Yang, P. Liu, and M. C. Yang, "The experimental and theoretical research on creep effect of large prestressed concrete box girder," Applied Mechanics and Materials, vol. 501-504, pp. 1199-1203, 2014. 
[27] M. Elbadry, A. Ghali, and R. B. Gayed, "Deflection control of prestressed box girder bridges," Journal of Bridge Engineering, vol. 19, no. 5, Article ID 04013027, 2013.

[28] H. Huang, S.-S. Huang, and K. Pilakoutas, "Modeling for assessment of long-term behavior of prestressed concrete boxgirder bridges," Journal of Bridge Engineering, vol. 23, no. 3, Article ID 04018002, 2018.

[29] G.-H. Cao, J.-X. Hu, and K. Zhang, "Coupling model for calculating prestress loss caused by relaxation loss, shrinkage, and creep of concrete," Journal of Central South University, vol. 23 , no. 2, pp. 470-478, 2016.

[30] S. Biswal, D. H. Reddy, and A. Ramaswamy, "Reducing uncertainties in estimating long-time prestress losses in concrete structures using a hygro-thermo-chemo-mechanical model for concrete," Computers \& Structures, vol. 211, pp. 1-13, 2019.

[31] Comite Europeen De Normalisation, Eurocode 2: Design of Concrete Structures-Part 2: Concrete Bridges-Design and Detailing Rules, British Standards Institution, Brussels, Belgium, 2005.

[32] A. Ghali, R. Favre, and M. Elbadry, Concrete Structures: Stresses and Deformations: Analysis and Design for Serviceability, CRC Press, Boca Raton, FL, USA, 2018.

[33] S. D. Kim, Prediction of Long-Term Prestress Loss in Concrete Box Girder Bridges, UC San Diego, San Diego, CA, USA, 2009.

[34] P. B. Shing and A. Kottari, Evaluation of Long-Term Prestress Losses in Post-Tensioned Box-Girder Bridges, California Department of Transportation, Sacramento, CA, USA, 2011.

[35] M. K. Tadros, Prestress Losses in Pretensioned High-Strength Concrete Bridge Girders, Vol. 496, Transportation Research Board, Washington, DC, USA, 2003.

[36] Z. P. Bažant and J. Milan, Creep and Hygrothermal Effects in Concrete Structures, Springer, Basingstoke, UK, 2018. 